American J. of Engineering and Applied Sciences 3 (2): 412-417, 2010

ISSN 1941-7020

(C) 2010 Science Publications

\title{
The Effect of Spring Design as Return Cycle of Two Stroke Spark Ignition Linear Engine on the Combustion Process and Performance
}

\author{
${ }^{1}$ A.Z.M. Fathallah and ${ }^{2}$ R.A. Bakar \\ ${ }^{1}$ Department of Marine Engineering, Institute Technology of Sepuluh Nopember, Surabaya, Indonesia \\ ${ }^{2}$ Faculty of Mechanical Engineering, University Malaysia Pahang Lebuhraya Tun Razak, \\ 263000 Gambang, Kuantan, Pahang, Malaysia
}

\begin{abstract}
Problem statements: The effects of optimization on spring design of the linear engine with spring mechanism in its performance and combustion process have been examined. However, at certain conditions the engine can not work properly as predicted. This can happen because displacement of engine stroke is depending on thrust forces of combustion process in cylinder of the engine. For that, some speed range can not open the scavenging ports, some speed can not open properly and most speeds range work normal. Moreover, pressure ratio also decrease depend on deflection of spring characteristics. Approach: This research examined the performance of engine at certain conditions in which displacement of spring did not work normal, such at $1,4.1$ and $4.6 \mathrm{~m} \mathrm{sec}^{-1}$ speed. It was necessary to examine because at that speeds intake scavenging port did not open properly. Therefore, simulation technique had been adopted to solve of the problems. Results: The combustion pressure and power output were compared with prediction result. Conclusion: The results were significant drop of Indicated Mean Effective Pressure (IMEP) and impacted reduced in power output. At three parts only $1 \mathrm{~m} \mathrm{sec}^{-1}$ speed of linear engine could work normal.
\end{abstract}

Key words: Linear engine, spring, performance

\section{INTRODUCTION}

Two stroke spark ignition linear engine with spring mechanism have been promoted as alternative engine to generate alternator. The design is compact and light, recommended to use for small generator. The competitiveness value is high compared with conventional two stroke spark ignition engine, although the working area has been changed. The concept of linear engine is to eliminate certain friction to conduct more extra power. Hooks law of spring affected the performance of linear engine. However, deflection of spring depending on thrust force. For that reason, the performance of linear engine is dependent on the result of optimization of spring design.

The advantages of spring as return cycle are very simple and compact, high response to expansion and compression in oscillation cycles. It is possible to accelerate very fast. A disadvantage of spring system for linear engine is dependable of deflection with thrust force from combustion process result. To eliminate the weakness of spring it necessary to optimized geometry design. It is needed to compromise between linear engine performances with spring design requirement.
Fathallah and Bakar (2009) predicted the performance of linear engine with spring mechanism. However, the optimization of spring design succeeding examine including its effect on inlet scavenging port and pressure ratio. Based on those report it need comprehensive studies the effects of optimization on spring design of the linear engine with spring mechanism on its combustion process and performance.

Accordingly, deflection of spring in certain speed could not open scavenging port properly. Beside that, the pressure ratio also drops depending on reducing of deflection of piston stroke (Mikalsen and Roskilly, 2008a). Both weaknesses affect the performance of linear engine with spring mechanism. The objective of research is concerning on certain speeds such performance at 1, 4.1 and $4.6 \mathrm{~m} \mathrm{sec}^{-1}$ speeds. Because spring deflection did not work properly at that speeds and need clearly analysis.

To investigate degradation of linear engine performance which is affected of spring design result, it's necessary to examined using specific parameter. In this research has been compared with prediction performance as conducted before (Fathallah and Bakar,

Corresponding Author: A.Z.M. Fathallah, Department of Marine Engineering, Institute Technology of Sepuluh Nopember, Surabaya, Indonesia Tel: +60169637250 Fax: +62315994754 
2009). Comparison study was only focusing on basic engine performance such as power output and indicated mean effective pressure.

\section{MATERIALS AND METHODS}

Linear engine design and research methods: The linear engine design result configuration is show in Fig. 1. This design starts from predicting the performance engine, optimization of spring geometry and finally design of linear engine with spring as return cycle. Optimization of spring design was necessary, because the linear engine should work on variable speed and load as originally of conventional engine. According to the result of prediction of the performance, there was very large range of Indicated Mean Effective Pressure (IMEP). Start from smallest to largest pressure, which is small pressure at maximum and minimum speeds and largest pressure at maximum torque. As the result was sophisticated spring geometry that should accommodate some speeds and loads. In fact, not all speeds and loads of engine can be handling by spring deflection properly, especially at small pressure. But, it is still compromise to maximization of speeds range.

According of the Fig. 1A, the piston position is in Top Dead Center (TDC). In this position the spring force is smallest, after combustion occur the pressure increases rapidly then expands the volume of cylinder, compressed spring and deflected to Bottom Dead Center (BDC). According to the original conventional engine, the oscillation of piston is $30.5 \mathrm{~mm}$. At that operation, the scavenging is working properly. However, the hooks law of spring effected on the displacement of the piston.
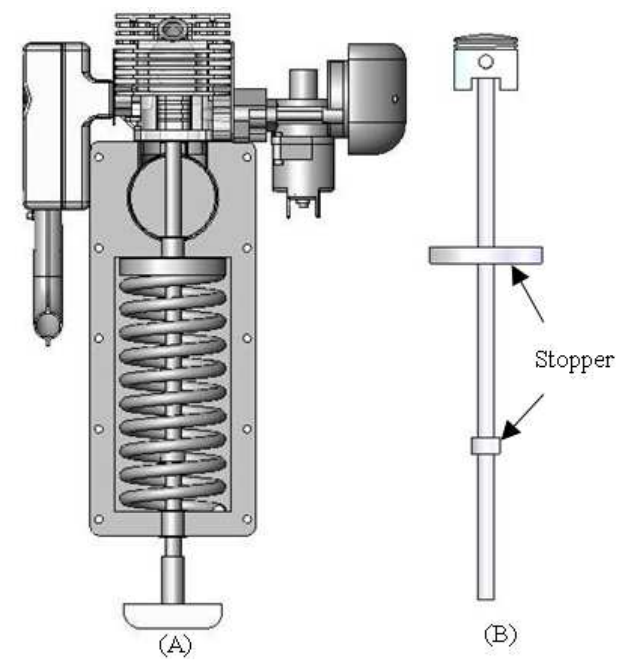

Fig. 1: Design of linear engine with spring mechanism
If the IMEP is too low then deflection of spring should be small and if the IMEP is too high then deflection should be large. For that reason it needs stopper when the deflection is higher then $30.5 \mathrm{~mm}$. Figure $1 \mathrm{~B}$ is stopper design of spring system on single cylinder SI linear engine.

To study the single cylinder SI linear engine performance, simulation has been used. GT Power has been used to simulate of the research. Simulation technique was similar with Fathallah and Bakar (2009) with small modification. Figure 2 is Flow chart of the model design analysis. A real engine specification has been used in this study. The main specifications of the engine are shown in Table 1 and 2 is geometry of spring design optimization result.

Table1: Engine specifications

\begin{tabular}{lll}
\hline Parameter & Unit & Value \\
\hline Model & & BG-328 \\
Type & - & $\begin{array}{l}\text { 2 cycle, single cylinder, air cooled, } \\
\text { gasoline engine }\end{array}$ \\
Bore & $\mathrm{mm}$ & 36 \\
Displacement & $\mathrm{mm}$ & 30.5 \\
Max output & $\mathrm{kW} \mathrm{rpm}{ }^{-1}$ & $0.81 / 6000$ \\
Carburetor & - & Float type \\
Ignition system & - & IC ignition (solid state) \\
Fuel & - & $\begin{array}{l}\text { Mixed fuel of gasoline and 2 cycle } \\
\text { oil at 25:1 }\end{array}$ \\
\hline
\end{tabular}

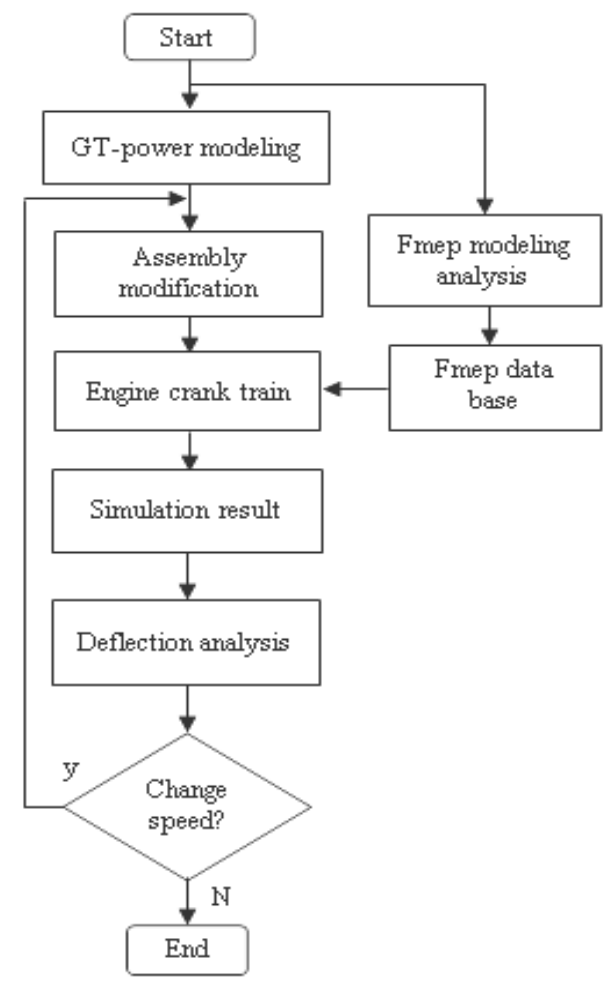

Fig. 2: Flow chart of the model design analysis 
The simulation modifications of GT power model were cylinder geometry, scavenging port, intake port and exhaust port. The assembly should be modified every change of spring deflection. As cylinder geometry was changed in stroke and compression ratio. Angle start of port overlap and angle at last port closed also modified depending on spring deflection. The same condition the scavenging ratio was modified and should be a justified with spring deflection. The crank angle array and area array at intake port and exhaust port were modified and should match with deflection angle of spring systems.

After assembly was modified then continue conducting data including combustion characteristics and engine performance. PV diagrams have been used to compare the combustion process and power output to compare the performance engine. In this research focusing was paid at $1,4.1$ and $4.6 \mathrm{~m} \mathrm{sec}^{-1}$ speed respectively because according linear engine design result at that speeds, the spring did not deflect properly. The assembly should be modified every speed was changed. All of data were recorded and compared with predicted data.

The Indicated Mean Effective Pressure (IMEP) has been examined with hooks law formula. If spring can not deflect higher than $25 \mathrm{~mm}$, then the intake scavenging port is not open and resulted that engine was misfired. Below is formula to calculate spring deflection (Petele, 2009):

$\mathrm{s}=\frac{8 \cdot \text { F.n. } \mathrm{D}^{3}}{\mathrm{G} \cdot \mathrm{d}^{4}}$

Where:

$\mathrm{s}=$ Spring deflection $(\mathrm{mm})$

$\mathrm{F}=$ Loading of spring (piston force) $(\mathrm{N})$

$\mathrm{n}=$ Number of active coil

$\mathrm{D}=$ Mean spring diameter $(\mathrm{mm})$

$\mathrm{G}=$ Modulus of elasticity in shear (MPa)

$\mathrm{d}=$ Wire diameter $(\mathrm{mm})$

Table 2: Geometry of spring design

\begin{tabular}{llr}
\hline Spring material: & \multicolumn{2}{l}{$\begin{array}{l}\text { Chrome-vanadium } \\
\text { alloy steel wire SAE 6150 }\end{array}$} \\
Direction of coil winding: & $\begin{array}{l}\text { Right } \\
\text { Surface treatment: }\end{array}$ & Shot peened springs \\
\hline Wire diameter $(\mathrm{mm})$ & $\mathrm{d}$ & 7.00 \\
Number of active coils & $\mathrm{n}$ & 10.00 \\
Outer spring diameter $(\mathrm{mm})$ & $\mathrm{De}$ & 57.70 \\
Inner spring diameter $(\mathrm{mm})$ & $\mathrm{Di}$ & 43.70 \\
Free spring length $(\mathrm{mm})$ & $\mathrm{L} 0$ & 200.00 \\
Preloaded spring length $(\mathrm{mm})$ & $\mathrm{L} 1$ & 147.32 \\
Fully loaded spring length $(\mathrm{mm})$ & $\mathrm{L} 2$ & 116.70 \\
Theoretic spring limit length $(\mathrm{mm})$ & $\mathrm{L} 3$ & 84.00 \\
\hline
\end{tabular}

Accordingly, the spring system of linear engine force is sum of the minimum load and combustion pressure load. The minimum load is the force of compression cycle; according to the original conventional engine, the design of compression ratio is 9. However, the force of combustion pressure is depending on the result of Indicated Mean Effective Pressure (IMEP). The equation below is the formula to calculate piston force:

$\mathrm{F}=\mathrm{F}_{\min }+\mathrm{F}_{\mathrm{IMEP}}$

The force is calculated from multiply of pressure with piston. The formula is shown in the equation number 3 below:

$\mathrm{F}=\mathrm{P} . \mathrm{A}$

\section{RESULTS}

The research is concern to the effect of spring design on performance and combustion process of linear engine. The comparison studies of performance result shows in Table 3. The different trends of combustion process show in Fig. 3-5. Figure 3 is PV diagram both predicted and designed at $1 \mathrm{~m} \mathrm{sec}^{-1}$ speed. However, Fig. 4 and 5 are different trend at 4.1 and $4.6 \mathrm{~m} \mathrm{sec}^{-1}$ speeds respectively.

Table 3 is the effect of characteristics of spring design on performances of linear engine. As recorded in Table 3 focusing at $1,4.1$ and $4.6 \mathrm{~m} \mathrm{sec}^{-1}$. Although intake scavenging port were opened at $1,4.1$ and $4.6 \mathrm{~m} \mathrm{sec}^{-1}$ speeds the intake scavenging port only open $56.4 \%$ at $1 \mathrm{~m} \mathrm{sec}^{-1}$ speed, $66.6 \%$ at 4.1 and $31.1 \%$ at $4.6 \mathrm{~m} \mathrm{sec}^{-1}$. The most speeds were deflecting properly.

According to Table 3, the different of power output between prediction and design result at $1 \mathrm{~m} \mathrm{sec}^{-1}$ speed slightly decreased from $0.24-0.23 \mathrm{~kW}$.

Table 3: Effect spring design on performance engine

\begin{tabular}{lrrrrrr}
\hline & $1 \mathrm{~m} \mathrm{sec}^{-1}$ & & \multicolumn{2}{c}{$4.1 \mathrm{~m} \mathrm{sec}^{-1}$} & \multicolumn{2}{c}{$4.6 \mathrm{~m} \mathrm{sec}^{-1}$} \\
& \multicolumn{1}{c}{ Pred } & \multicolumn{1}{c}{ Des } & Pred & \multicolumn{1}{c}{ Des } & \multicolumn{1}{c}{ Pred } & \multicolumn{1}{c}{ Des } \\
\hline Brake power (kW) & 0.240 & 0.230 & 1.03 & 0.51 & 1.60 & 0.13 \\
Brake torque (N-m) & 2.200 & 1.900 & 2.40 & 1.10 & 2.20 & 0.30 \\
IMEP (Bar) & 5.540 & 5.300 & 5.66 & 3.18 & 5.24 & 0.73 \\
Air flow rate & 2.000 & 1.400 & 4.30 & 2.30 & 4.40 & 0.70 \\
(kg h $^{-1}$ ) & & & & & & \\
BSFC (g kW & & & & & & \\
Volumetric & 690.600 & 595.900 & 347.10 & 412.40 & 351.00 & 301.00 \\
efficiency (\%) & 92.500 & 75.700 & 50.00 & 28.80 & 45.70 & 8.40 \\
Trapping ratio & & & & & & \\
A/F ratio & 0.798 & 0.954 & 1.00 & 1.00 & 1.00 & 1.00 \\
Brake efficiency (\%) & 12.400 & 12.360 & 12.23 & 12.03 & 12.11 & 15.90 \\
\hline & & 13.800 & 23.80 & 20.00 & 23.50 & 27.40 \\
\hline
\end{tabular}




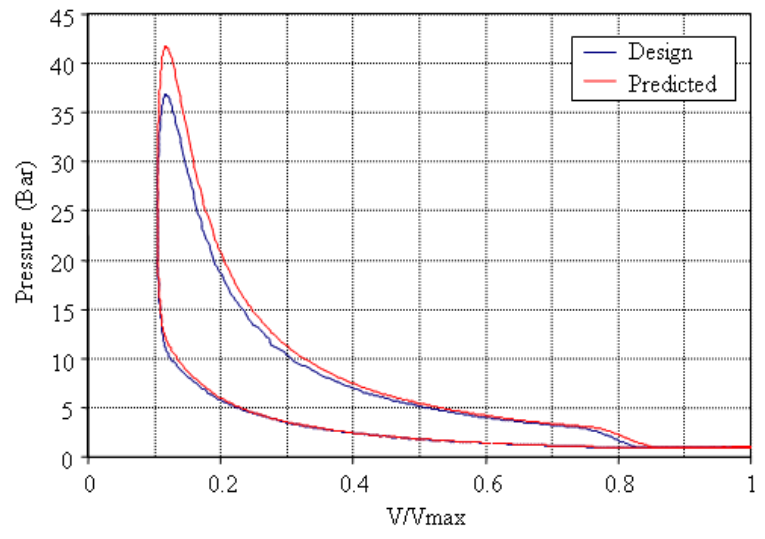

Fig. 3: Effect spring design on PV diagram at $1 \mathrm{~m} \mathrm{sec}^{-1}$ speed

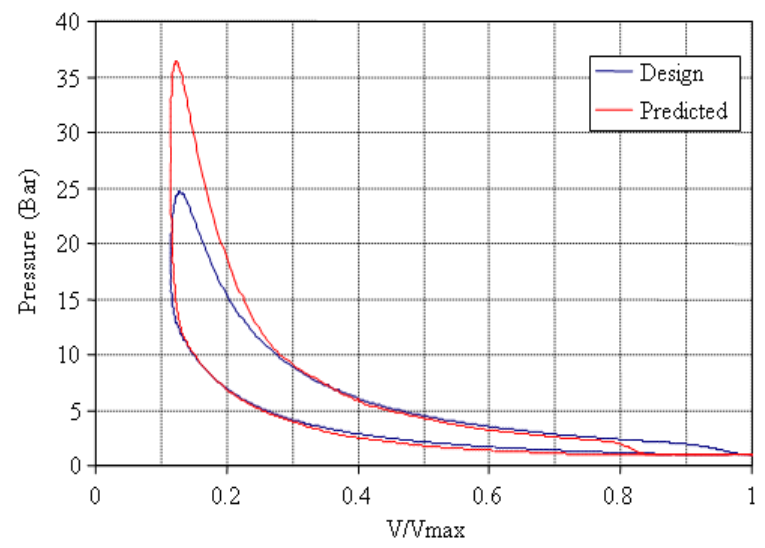

Fig. 4: Effect spring design on PV diagram at $4.1 \mathrm{~m} \mathrm{sec}^{-1}$ speed

However, at $4.1 \mathrm{~m} \mathrm{sec}^{-1}$ was double and dramatically decreased at $4.6 \mathrm{~m} \mathrm{sec}^{-1}$ speed. The similar trend also showed at brake torque, IMEP, air flow rate and volumetric efficiency. The Brake Specific Fuel Consumption (BSFC) and brake efficiency were unsystematically performance. However, design result at 1 and $4.6 \mathrm{~m} \mathrm{sec}^{-1}$ brake efficiency higher than predicted. At $4.1 \mathrm{~m} \mathrm{sec}^{-1}$ was opposed with predicted result, which higher than designed. BSFC also have same trend with brake efficiency.

Figure 3 is different trend of PV diagram at $1 \mathrm{~m} \mathrm{sec}^{-1}$ speed. The pressure maximum drop slightly as the result was decreasing the IMEP value. The prediction of IMEP at $1 \mathrm{~m} \mathrm{sec}$ was 5.54 Bar. However, the IMEP was decrease to 5.2 Bar on design performance. The IMEP was decrease about $6.1 \%$ at $1 \mathrm{~m} \mathrm{sec}^{-1}$ speed.

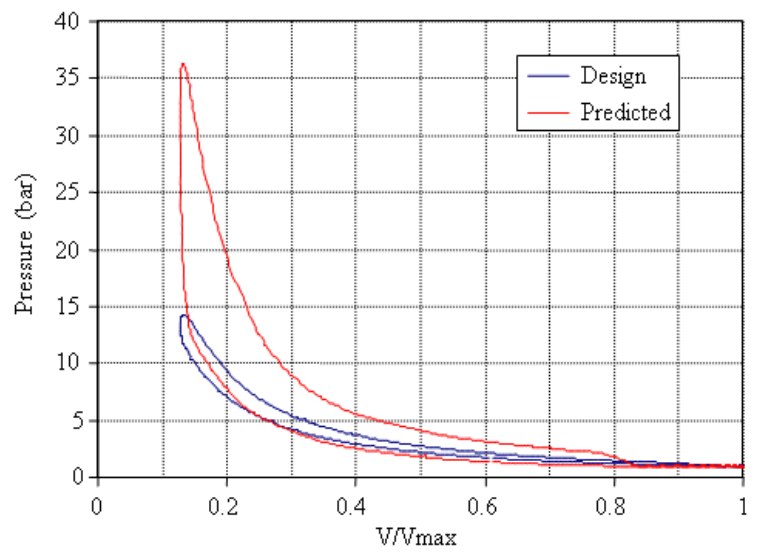

Fig. 5: Effect spring design on PV diagram at $4.6 \mathrm{~m} \mathrm{sec}^{-1}$ speed

Table 4: Effect of decreasing of IMEP on spring deflection

\begin{tabular}{llc}
\hline & Deflection $(\mathrm{mm})$ & \\
Piston speed $\left(\mathrm{m} \mathrm{sec}^{-1}\right)$ & Predict & Design \\
\hline 0.5 & 16.57 & 0.00 \\
1 & 26.95 & 25.36 \\
1.5 & 33.79 & 33.79 \\
2 & 36.87 & 36.87 \\
2.5 & 38.63 & 38.63 \\
3.1 & 36.09 & 36.09 \\
3.6 & 31.02 & 31.02 \\
4.1 & 27.66 & 18.75 \\
4.6 & 25.18 & 4.30 \\
5.1 & 22.24 & 0.00 \\
5.6 & 19.11 & 0.00 \\
6.1 & 15.98 & 0.00 \\
\hline
\end{tabular}

Figure 4 is PV diagram at $4.1 \mathrm{~m} \mathrm{sec}^{-1}$ speed. The pressure maximum was decrease from 36.34-24.57 Bar. The IMEP also decrease from 5.66-3.18 Bar. More sophisticated degradable characteristic is in engine speed $4.6 \mathrm{~m} \mathrm{sec}^{-1}$. The pressure maximum was decrease from 36.34-14.19 Bar and IMEP decrease from 5.240.73 Bar. Figure 5 is different trend of PV diagram between predicted and designed at $4.6 \mathrm{~m} \mathrm{sec}^{-1}$.

The effect of decreasing of IMEP impacted on cycle to cycle characteristics of linear engine. However, reducing the trend of IMEP was affect in spring oscillations. Base on hooks formula, the spring deflection examined and the result was tabulated at Table 4. Calculation in Table 4 only conducted at speed 1, 4.1 and $4.6 \mathrm{~m} \mathrm{sec}^{-1}$. However at 0.5, 5.1, 5.6 and 6.1 speeds did not need to examine because based on spring design optimization were resulted as misfired. According to Table 4, deflection in 1, 4.1 and $4.6 \mathrm{~m} \mathrm{sec}^{-1}$ were decreased. 


\section{DISCUSSION}

To conduct a large range of speeds in linear engine is necessary to optimize the design of spring. However, hooks low can not to ignore of this research. The engine performance and combustion process of linear engine are very sensitive with spring characteristics. Interaction between thrust forces which is produce from combustion process with spring could change the engine performance dynamically. Spring deflection could affect on characteristics of combustion process. The other hand product of combustion could affect on spring deflection. The interaction both spring and combustion impacted in the basic performance of linear engine.

In fact the design performance less than predicted performance because it is not easy to match between the best engine performance with spring characteristics. Decreasing engine performance is causing some factor including imperfect scavenging process and decreasing of pressure ratio. Unstable oscillations of piston movement impacted the intake scavenging port did not open properly, consequently disturbed the mixture supply to combustion chamber. Not only had that, decreasing oscillations of piston also reduced compression ratio as the penalty is smaller efficiency. The indicated mean effective pressure also decreased (John, 1988). Table 3 is very clear result that different performance between predicted and designed. Compression ratio also affected by compression energy (Mikalsen and Roskilly, 2008b). In case of linear engine with spring mechanism, the return cycle is following of hooks lows. The oscillation energy is conducted by thrust force of combustion product. The pressure ratio is depend of spring deflection, if deflection decreased from oscillation design than will decrease linear with thrust force.

Air flow rate is very important for process of combustion; insufficient air could affect imperfect combustion and resulted smaller of the IMEP. In table 3 , show that air flow rate at prediction increased with rising engine speed. The other hand, air flow rate was decreased at design condition. This phenomenon due to improperly scavenging process as the penalty was smaller IMEP performance. From Fig. 3-5 are clear shows that predicted PV diagram higher than designed. According to definitions on a mass fraction burned duration should be increased with increasing of engine speed (John, 1988). Similar trend result also conducted by another researcher (Atkinson et al., 1999), which work on constant load resulted increasing of peak pressure. More clear theory is explained by Colin and Kirkpatrick (2001).
In two-stroke engines, performance and combustion stability strongly depend on scavenging process, where burn gases are flushed out of the cylinder and replaced by the intake mixture (Kleemann et al., 2004). Lacking intake scavenging port is high contribution to reduced performance and combustion process. More small space of intake scavenging port, the degradable of performance and combustion process more strong affected. Figure 3-5 are very clear result that combustion process effected by improperly of intake scavenging. Table 3 is also clear result of engine performance. Correlations between air flow rate with IMEP, torque and power output very strong connected.

Improperly scavenging process at 1,4.1 and $4.6 \mathrm{~m} \mathrm{sec}^{-1}$ speeds affected the IMEP characteristics. Smaller IMEP resulted smaller thrust force at piston spring system. Therefore spring deflection decreased, if spring oscillations less than $25 \mathrm{~mm}$ than the intake scavenging port do not open and resulted misfire in combustion chamber. According to Table 4, although the deflection at $1 \mathrm{~m} \mathrm{sec}^{-1}$ was decreased but still can opened intake scavenging port. However, did not enough deflections for 4.1 and $4.6 \mathrm{~m} \mathrm{sec}^{-1}$ speeds as the result were misfired. Finally only 50\% range speeds could works properly. According to the prediction performance, the best power output was $1.06 \mathrm{~kW}$ at $4.6 \mathrm{~m} \mathrm{sec}^{-1}$ speed (Fathallah and Bakar, 2009). The real design result was $1.03 \mathrm{~kW}$ at $3.6 \mathrm{~m}$ $\mathrm{sec}^{-1}$ speed. Although the optimum design result only $1.03 \mathrm{~kW}$, it is better than performance of conventional engine. The best performance of conventional engine was $0.93 \mathrm{~kW}$ at $4.6 \mathrm{~m} \mathrm{sec}^{-1}$ speed.

\section{CONCLUSION}

The effect of spring design as return cycle of two strokes spark ignition linear engine on its combustion process and performance has been studies in this research. The combustion process and performance were compared with predicted result. In general at three focused speeds, the combustion and performance were decreased. Although decreasing in combustion and performance at $1 \mathrm{~m} \mathrm{sec}^{-1}$ speed is still promised well running. The other hand at 4.1 and $4.6 \mathrm{~m} \mathrm{sec}^{-1}$ speeds are misfired because significantly decreasing in deflection of spring.

From 12 speeds as variables only $50 \%$ range speed could working properly. Although range speeds was decreased comparing with conventional engine, however, the maximum power output is still higher. The final design result was $1.03 \mathrm{~kW}$ at $3.6 \mathrm{~m} \mathrm{sec}^{-1}$. 
Am. J. Engg. \& Applied Sci., 3 (2): 412-417, 2010

\section{ACKNOWLEDGMENT}

The present research was funded by Grant of Research, University Malaysia Pahang (GRS 070123). Special thanks to Mr. Ismail Ali for assisted research preparation.

\section{REFERENCES}

Atkinson, C.M., S. Patreanu, N.N. Clark, R.J. Atkinson and T.I. McDaniel et al., 1999. Numerical simulation of a two-stroke linear engine-alternator combination. SAE Technical Paper Ser. 1999-020921. http://www.sae.org/technical/papers/199901-0921

Colin, R.F. and A.L. Kirkpatrick, 2001. Internal Combustion Engine Applied Thermosciences. 2nd Edn., John Wiley and Sons, ISBN: 0-47135617-4, pp: 82-103.

Fathallah, A.Z.M. and R.A. Bakar, 2009. Prediction studies for the performance of a single cylinder high speed spark ignition linier engine with spring mechanism as return cycle. Am. J. Eng. Applied Sci., 2: 720-727.
John, B.H., 1988. Internal Combustion Engine Fundamentals. McGraw Hill Book Company, ISBN: 13: 9780070286375, pp: 748-770.

Kleemann, A.P., J.C. Dabadie and S. Henriot, 2004. Computational design studies for a high-efficiency and low-emissions free piston engine prototype. SAE Technical Paper Ser. 2004-01-2928. http://www.sae.org/technical/papers/2004-01-2928

Mikalsen, R. and A.P. Roskilly, 2008a. Performance simulation of a spark ignition free-piston engine generator. Applied Therm. Eng., 28: 1726-1733. DOI: 10.1016/j.applthermaleng.2007.11.015

Mikalsen, R. and A.P. Roskilly, 2008b. Couple dynamic-multidinemensional modeling of freepiston engine combustion. Applied Eng., 85: 89-95. DOI: 10.1016/j.apenergy.2008.04.012

Petele, M., 2009. Spring calculation. http://www.mitcalc.com/doc/springs/help/en/spring s.htm 